\title{
РЕЙТИНГОВЫЕ ИССЛЕДОВАНИЯ КАЧЕСТВА ИНСТИТУТОВ КАК КОЛИЧЕСТВЕННЫЕ ОЦЕНКИ КАЧЕСТВА ИНСТИТУЦИОНАЛЬНОЙ СРЕДЫ
}

\author{
(C) 2021 Бенсон Изабель Назиховна \\ Россия, Санкт-Петербург \\ E-mail: Benson.isabel@gmail.com
}

Статья посвящена исследованию проблемы количественного оценивания качественных характеристик институциональной среды. Показано, что существующие рейтинговые исследования, при различии методологии их составления и характера используемых данных, дают согласованные оценки, позволяющие получить объективную информацию о качестве институтов. Доказано, что индексы качества институциональной среды, оценивающие ее отдельные параметры могут быть использованы в качестве количественной характеристики не только отдельных ее составляющих, но и качества институтов в целом.

Ключевые слова: качество институтов, формальные и неформальные институты, институциональная среда.

Воздействие институтов на устойчивость экономического роста, его темпы, достигаемый странами уровень благосостояния, на сегодняшний день уже не является предметом дискуссий. Однако характер этого воздействия, его значимость в сравнении с традиционно учитываемыми факторами, такими как накопленный человеческий капитал, инвестиции и инновации, остаются активно осваиваемым полем исследований. Одна из сложностей оценки влияния институтов на рост является неопределенность их количественной оценки. Одним из потенциально возможных способов построения такой количественной оценки является использование информации, предоставляемой различными рейтингами оценки качества институциональной среды. Проверяемая в данной статье гипотеза заключается в том, что индексы, оценивающие различные параметры качества институциональной среды, основывающиеся как на частично совпадающей, так и на полностью независимой информационной базе, построенные на различной методологии расчета, дают согласованные оценки. Именно эти оценки могут использоваться в качестве количественного отражения качества институтов.

Связь институтов с устойчивостью долгосрочного роста. Обзор позиций.

Различия в темпах экономического роста и уровне экономического развития не получали должного объяснения в рамках неоклассических подходов и только институциональный анализ предложил объяснение межстрановых отличий. Д.Норт обосновал необходимость стимулирования деятельности со стороны институциональной системы для побуждения к росту наряду с наличием труда, капитала и знаний [8]. Концепция инклюзивных и экстрактных институтов [1] связывает потенциал долгосрочного роста с преобладанием инклюзивных институтов. Д. Остерфельд выводит потенциал устойчивого роста из свободы работы рыночных механизмов, которым не должны препятствовать распределительные усилия правительства [12].

Российские экономисты проявляют особый интерес к концепции ресурсного проклятия, в соответствии с которой плохие институты не позволяют использовать ренту для развития, а сама рента консервирует плохие институты $[9,4]$.

Страны, в которых сформирована благоприятная для экономического развития институциональная среда, характеризуются более высокие показателями благосостояния населения. Но в то же время невозможно привести примеры экономик, характеризующихся высокими показателями благосостояния населения и низкими показателями качества институциональной среды.

Институциональный подход становится неотъемлемой частью экономической теории, поскольку значимость институтов в экономическом развитии доказана многими исследователями и уже не подвергается сомнению или опровержению. Если классическая и неокласси- 
ческая экономическая теория в качестве фактора роста использует величину инвестиций в интеллектуальный и основной капитал, то институциональный подход рассматривает институты как объясняющий фактор величины инвестиций [2].

Таким образом, добавление категории «институт» в экономический анализ позволяет получать более содержательные выводы. Сама эта категория может трактоваться достаточно широко в зависимости от контекста исследований. Далее под институтами будет пониматься набор правил, которые ограничивают поведение экономических агентов, упорядочивают взаимодействие между ними и формируют стимулы к деятельности, а также соответствующие механизмы контроля над соблюдением установленных правил [10]. В этой совокупности ограничений важно различать формальные правила, неформальные ограничения (общепринятые поведенческие установки. Согласно определению Д.Норта, неформальные правила или институты являются связующим звеном между формальными правилами (законами) и убеждениями, разделяемыми людьми [7]. Неформальные институты по своей сути являются кодексами поведения или культурой, дополняющей формальные правила.

При оценке качества институтов необходимо оценивать не только качество формальных правил, но и аспекты их соблюдения, поскольку институтом считается только такая норма, которая соблюдается всеми членами общества. Формально существующие правила, но игнорируемые на практике - институтами не являются.

Институты в своей совокупности образуют целостную систему с взаимосвязанными и взаимообусловленными элементами - институциональную среду. Среди работ, посвященных исследованию качества институциональной среды, можно особо выделить труды Д.Норта и С. Г. Кирдиной. Их позиции совпадают в том, что институциональная среда является устойчивой к фрагментарным изменениям, но способна эволюционировать вместе с обществом обеспечивая его целостность в условиях меняющейся окружающей среды [7, 5]. В работе Лякина А.Н. и Бенсон И.Н. доказано, что институциональная среда является устойчивой, но подвержена изменениям под внешним воздействием. Включение экономик в интеграционные процессы является фактором, обеспечивающим эволюцию сложившихся в них институтов [11].

В работах Д.Норта не содержится содержательного определения качественных институтов, он исследует институты с точки зрения создания условий для эффективной работы организаций. Если рассматривать институты как набор механизмов и правил, обеспечивающих перераспределение ресурсов в экономике, то качественными институтами будут являться те, которые способствуют повышению эффективности экономической деятельности.

Основываясь на изучении методологии и общих принципов построения рейтинговых исследований, можно прийти к выводу, что индикаторами качества институтов выступают следующие характеристики институциональной среды: низкий уровень коррупции, наличие эффективных механизмов защиты прав собственности, высокая степень независимость судебной власти и т.д.

Более удобен для интерпретации подход С.Г.Кирдиной, который разделяет институты на свойственные X-матрицам (верховная условная (не частная) собственность, институт редистрибуции или распределения, кооперация, служебный труд, ограничение издержек) и Ү-матрицам (частная собственность, рыночные обмен, конкуренция, наемный труд и максимизации прибыли) [5]. Исходя из методологии составления рейтинговых исследований, лучшими институтами признаются институты, созданные в Y-матрицах, поскольку именно они позволяют добиться более высокого уровня развития экономики. Такие аспекты как инновационная и инвестиционная активность присущи экономикам с доминирующими институтами из Y институциональных матриц.

\section{Рейтинги качества институциональной} среды

Исследование институциональных изменений и различий возможно посредством использования количественных оценок и рейтингов. В настоящее время доступен целый ряд регулярно обновляемых индексов и рейтингов, содержащих оценки качественных характеристик отдельных параметров институциональной среды.

Наиболее известные рейтинговые исследования можно разделить на три группы: исследования, оценивающие правовые институты, регулирующие институты, институты развития человеческого потенциала (Таблица 1).

Правовые институты оценивают индекс 
Таблица 1. Индексы, оценивающие эффективность институциональной среды

\begin{tabular}{|c|c|c|}
\hline Правовые институты & Регулирующие институты & $\begin{array}{c}\text { Институты развития человеческо- } \\
\text { го потенциала }\end{array}$ \\
\hline $\begin{array}{l}\text { 1. The Rule of Law Index } \\
\text { 2. The International Property Right } \\
\text { Index } \\
\text { 3. Worldwide Government Indicators }\end{array}$ & $\begin{array}{l}\text { 1. The International Property Right } \\
\text { Index } \\
\text { 2. Index of Economic Freedom } \\
\text { 3. Worldwide Government Indicators } \\
\text { 4. Doing Business }\end{array}$ & $\begin{array}{l}\text { 1. Human Development Index } \\
\text { 2. Knowledge Economy Index }\end{array}$ \\
\hline
\end{tabular}

Источник: составлено автором

верховенства права, международный индекс защиты прав собственности, индекс качества государственного управления. Регулирующие институты оценивают международный индекс защиты прав собственности, индекс экономической свободы, индекс качества государственного управления, рейтинг легкости ведения бизнеса. Институты развития человеческого потенциала оцениваются в индексах развития человеческого потенциала и экономики знаний.

Методология составления индекса качества государственного управления обсуждается в работе Мзокова А.Р., остальных индексов - в работе Бенсон И.Н. Методы прямых измерений определенных параметров институциональной среды используются при составлении рейтинга легкости ведения бизнеса. Данные макроэкономической статистики используются в индексах качества государственного управления, развития человеческого потенциала, экономики знаний и экономической свободы. Индекс верховенства закона основывается только на информации, полученной опросным методом [6, 3].

Источники данных для расчета перечисленных ранее индексов сведены в таблицу 2. Из нее мы видим, что построение большинства из них производится на основании сочетания методов экспертных оценок, анкетирования и исследо-

Таблица 2. Сравнительная характеристика индексов качества институциональной среды

\begin{tabular}{|c|c|c|c|c|}
\hline № & Индекс & $\begin{array}{l}\text { Организация } \\
\text { исследования }\end{array}$ & Тип исследования & Источники данных \\
\hline 1 & $\begin{array}{l}\text { Качество государ- } \\
\text { ственного управления } \\
\text { (Worldwide Governance } \\
\text { Indicators) }\end{array}$ & The World Bank & Рейтинг, индекс & $\begin{array}{l}\text { Статистические данные, } \\
\text { опрос населения и руко- } \\
\text { водителей компаний }\end{array}$ \\
\hline 2 & $\begin{array}{l}\text { Индекс легкости ве- } \\
\text { дения бизнеса (Doing } \\
\text { Business) }\end{array}$ & The World Bank & $\begin{array}{l}\text { Экспертно- } \\
\text { аналитическое, рейтинг }\end{array}$ & $\begin{array}{l}\text { Прямые измерения от- } \\
\text { дельных характеристик } \\
\text { институциональной } \\
\text { среды }\end{array}$ \\
\hline 3 & $\begin{array}{l}\text { Индекс верховенства } \\
\text { закона (The Rule of Law } \\
\text { Index) }\end{array}$ & The World Justice Project & $\begin{array}{l}\text { Экспертно- } \\
\text { аналитическое, рейтинг, } \\
\text { индекс }\end{array}$ & $\begin{array}{l}\text { Опросы экспертов и } \\
\text { рядовых граждан }\end{array}$ \\
\hline 4 & $\begin{array}{l}\text { Международный индекс } \\
\text { защиты прав собствен- } \\
\text { ности (The International } \\
\text { Property Right Index) }\end{array}$ & $\begin{array}{l}\text { The Property Rights } \\
\text { Alliance }\end{array}$ & $\begin{array}{l}\text { Экспертно- } \\
\text { аналитическое, рейтинг, } \\
\text { индекс }\end{array}$ & $\begin{array}{l}\text { Синтез индексов } \\
\text { восприятия корруп- } \\
\text { ции, государственного } \\
\text { управления, глобальной } \\
\text { конкурентоспособности }\end{array}$ \\
\hline 5 & $\begin{array}{l}\text { Индекс экономики } \\
\text { знаний (The Knowledge } \\
\text { Economy Index) }\end{array}$ & The World Bank & Индекс, рейтинг & $\begin{array}{l}\text { Опросы экспертов, дан- } \\
\text { ные индекса Worldwide } \\
\text { Governance Indicator }\end{array}$ \\
\hline 6 & $\begin{array}{l}\text { Индекс экономиче- } \\
\text { ской свободы (Index of } \\
\text { Economic Freedom) }\end{array}$ & $\begin{array}{l}\text { The Heritage Foundation, } \\
\text { The Wall Street Journal }\end{array}$ & $\begin{array}{l}\text { Экспертно- } \\
\text { аналитическое, индекс }\end{array}$ & $\begin{array}{l}\text { Статистические данные, } \\
\text { данные индекса } \\
\text { Rule of Law Index }\end{array}$ \\
\hline 7 & $\begin{array}{l}\text { Индекс развития чело- } \\
\text { веческого потенциала } \\
\text { (Human Development } \\
\text { Index) }\end{array}$ & $\begin{array}{l}\text { United Nations } \\
\text { Development Programme } \\
\text { (UNDP) }\end{array}$ & $\begin{array}{l}\text { Экспертно- } \\
\text { аналитическое, индекс }\end{array}$ & $\begin{array}{l}\text { Статистические данные } \\
\text { ООН, международных } \\
\text { организаций, соответ- } \\
\text { ствующих профилю } \\
\text { исследуемых данных, } \\
\text { национальная стати- } \\
\text { стика }\end{array}$ \\
\hline
\end{tabular}

Источник: составлено автором 
вания макроэкономической статистики.

Субъективность оценок, присваиваемых странам в ряде индексов качества институциональной среды, требует проведения дополнительных исследований для обоснования достоверности информации, полученной опросными или экспертными методами. Также важно определить, на сколько отдельные индексы, оценивающие определенные институты оценивают качество институциональной среды в целом и в какое мере отдельные индексы могут быть корректно использованы для межстрановых сопоставлений.

Для ответа на поставленные вопросы остановимся на более подробном исследовании взаимосвязи информации, представленной в данных индексах (рисунок 1). На диаграмме, отображающей взаимосвязь информации линиями показаны пересечения оцениваемых в индексах параметров институциональной среды. Стрелки указывают на прямое заимствование информации из других исследований. Так, индекс Качества государственного управления заимствует информацию из исследований верховенства права, рейтинга стран по уровню защиты прав собственности и индекса экономической свободы. [6] Индекс экономической свободы, в свою очередь, использует информацию из исследования верховенства закона, а индекс экономики знаний использует количественные данные из исследования качества государственного управления [3].

Мы видим, что индексы, оценивающие правовые и регулирующие институты тесно связаны между собой методологически. Индексы, оценивающие институты развития человеческого потенциала в наименьшей мере связаны с другими показателями. Так, индекс экономики знаний оценивает условия для эффективного использования существующих знаний и создания новых, то есть использует данные об эффективности работы правительств, оцениваемых в индексах качества государственного управления.

Большинство представленных индексов оценивают пересекающиеся параметры институциональной среды. (Таблица 3) Индексы верховенства закона, защиты прав собственности, экономической свободы и качества государ-

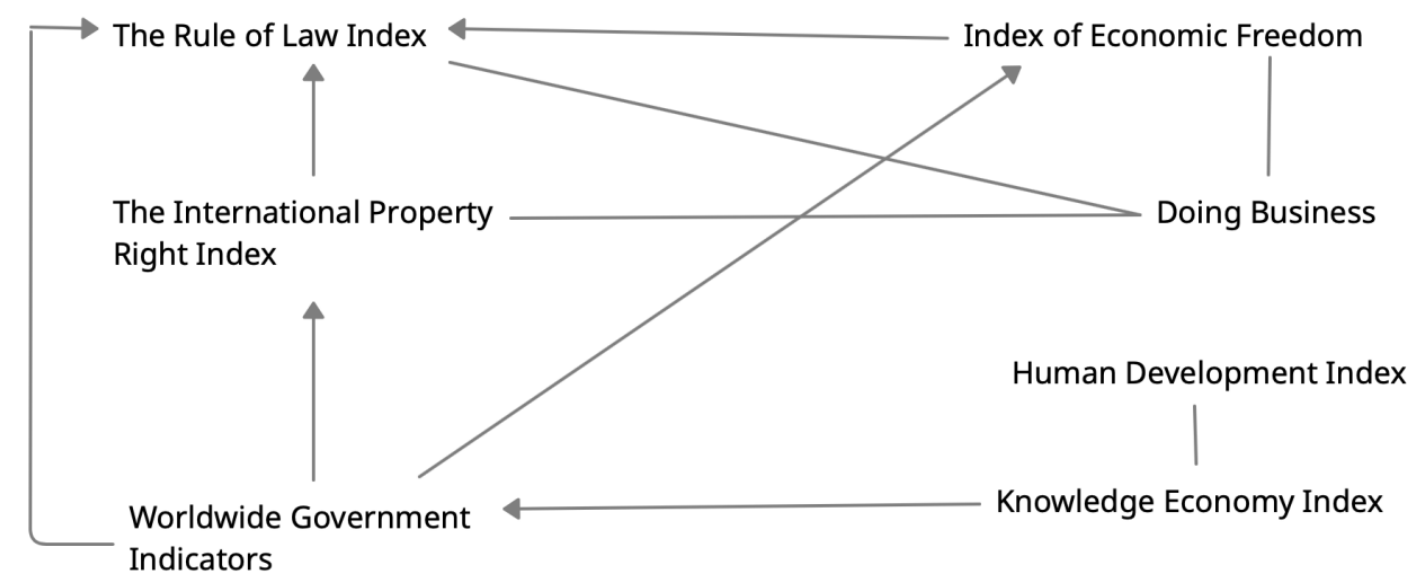

Рисунок 1. Методологические связи между индексами качества институциональной среды Источник: составлено автором

Таблица 3. Ядро индексов

\begin{tabular}{|c|c|c|c|}
\hline $\begin{array}{c}\text { Индекс верховенства } \\
\text { закона }\end{array}$ & $\begin{array}{c}\text { Индекс защиты прав } \\
\text { собственности }\end{array}$ & $\begin{array}{c}\text { Индекс экономической } \\
\text { свободы }\end{array}$ & $\begin{array}{c}\text { Качество государственно- } \\
\text { го управления }\end{array}$ \\
\hline $\begin{array}{l}\text { Уровень коррупции; } \\
\text { Защита основных прав } \\
\text { человека; } \\
\text { Соблюдение законов; } \\
\text { Гражданское и уголовное } \\
\text { правосудие. }\end{array}$ & $\begin{array}{l}\text { Уровень коррупции; } \\
\text { Независимость судебной } \\
\text { системы и беспристраст- } \\
\text { ность судов; } \\
\text { Верховенство закона; } \\
\text { Политическая стабиль- } \\
\text { ность. }\end{array}$ & $\begin{array}{l}\text { Уровень коррупции; } \\
\text { Защита прав собствен- } \\
\text { ности. }\end{array}$ & $\begin{array}{l}\text { Уровень коррупции; } \\
\text { Качество законодатель- } \\
\text { ства; } \\
\text { Верховенство закона; } \\
\text { Политическая стабиль- } \\
\text { ность. }\end{array}$ \\
\hline
\end{tabular}

Источник: составлено автором 
ственного управления оценивают такой важный параметр качества институциональной среды как уровень коррупции. Индексы защиты прав собственности и качества государственного управления оценивают политическую стабильность. Оценка ключевых правовых и регулирующих институтов составляет ядро индексов качества институциональной среды и является критерием качества институтов в соответствии с теоретическим подходом Д.Норта.

Исследование взаимосвязи информации в индексах и методологии их построения позволяет заключить, что в наименьшей мере между собой связаны исследования легкости ведения бизнеса и развития человеческого потенциала. Одним из способов, которым можно проверить согласованность оценок является корреляционный анализ.

Коэффициент корреляции Спирмена (таблица 4) для индексов легкости ведения бизнеса и развития человеческого потенциала составляет $-0,765$. Полученное значение коэффициента корреляции говорит о высокой тесноте связи между оценками, а знак «-» является следствием того, что у индексов взаимообратные шкалы. В индексе развития человеческого потенциала высокие значения присваиваются экономикам с лучшими условиями для развития человеческого потенциала, а в индексе легкости ведения бизнеса лучшим экономикам с точки зрения легкости ведения бизнеса присваиваются наименьшие значения - такие страны занимают первые позиции в рейтинге.

Рассмотрим коэффициенты корреляции между индексами, использующими субъективные и объективные данные. Как уже упоминалось выше, исследование легкости ведения бизнеса использует прямые измерения отдельных характеристик институциональной среды и в данном контексте может считаться достаточно объективным. Все коэффициенты корреляции по модулю выше 0,7. Высокое значение коэффициента корреляции говорит о высокой тесноте связи и наличии согласованности между оценками, полученными в различных рейтинговых исследованиях качества институциональной среды.

Чисто субъективный индекс верховенства закона показывает очень высокую тесноту связи с остальными индексами. Методологически индекс верховенства закона не связан с индексами развития человеческого потенциала и экономики знаний, а коэффициенты корреляции составляют 0,873 и 0,905 соответственно.

Таким образом, согласованность оценок индексов, оценивающих различные аспекты институциональной среды, может служить свидетельством того, что информация, содержащаяся в различных индексах, является достоверной и не входит в противоречие с другими исследованиями качества институтов.

Анализ методологических пересечений показывает, что различные индексы качества правовых и регулирующих институтов оценивают

Таблица 4. Корреляционный анализ (коэффициенты корреляции Спирмена)

\begin{tabular}{|c|c|c|c|c|c|c|c|}
\hline & Rule of Law & $\begin{array}{l}\text { Property } \\
\text { Rights }\end{array}$ & $\begin{array}{l}\text { Government } \\
\text { Indicators }\end{array}$ & $\begin{array}{l}\text { Corruption } \\
\text { Perception }\end{array}$ & $\begin{array}{l}\text { Doing } \\
\text { Business }\end{array}$ & $\begin{array}{l}\text { Human De- } \\
\text { velopment } \\
\text { Index }\end{array}$ & $\begin{array}{l}\text { Knowledge } \\
\text { Economy } \\
\text { Index }\end{array}$ \\
\hline Rule of Law & 1 & $0,940^{\text {***: }}$ & $0,963^{\text {*** }}$ & $0,858^{* * *}$ & $-0,835$ ** & $0,873 * *$ & $0,905^{* * *}$ \\
\hline $\begin{array}{l}\text { Property } \\
\text { Rights }\end{array}$ & $0,940^{* * *}$ & 1 & $0,924^{* * *}$ & $0,821^{* * *}$ & $-0,840^{* * *}$ & $0,816^{* * * *}$ & $0,832^{* * * *}$ \\
\hline $\begin{array}{l}\text { Government } \\
\text { Indicators }\end{array}$ & 0,963 *** & $0,924^{* * *}$ & 1 & $0,884^{* * *}$ & $-0,827^{\text {*** }}$ & $0,887^{\text {**** }}$ & $0,917^{* * *}$ \\
\hline $\begin{array}{l}\text { Corruption } \\
\text { Perception }\end{array}$ & $0,858^{* * *}$ & $0,821^{* * *}$ & $0,884^{* * *}$ & 1 & $-0,701^{* * *}$ & $0,762^{* * *}$ & $0,798^{* * *}$ \\
\hline $\begin{array}{l}\text { Doing } \\
\text { Business }\end{array}$ & $-0,835^{* * *}$ & $-0,840 *$ & $-0,827 *$ & $-0,701^{* * *}$ & 1 & $-0,765^{* *}$ & $-0,802^{* * *}$ \\
\hline $\begin{array}{l}\text { Human } \\
\text { Development } \\
\text { Index }\end{array}$ & $0,873^{\text {*** }}$ & $0,816^{* * * *}$ & $0,887^{* * * *}$ & $0,762^{* * *}$ & $-0,765^{5 * *}$ & 1 & $0,969^{* * *}$ \\
\hline $\begin{array}{l}\text { Knowledge } \\
\text { Economy } \\
\text { Index }\end{array}$ & $0,905^{* * *}$ & $0,832^{* * * *}$ & $0,917^{* * * *}$ & $0,798^{* * *}$ & $-0,802^{* * *}$ & $0,969^{* * *}$ & 1 \\
\hline
\end{tabular}

**. Корреляция значима на уровне 0.01 (2-сторон.)

Источник: рассчитано автором 
повторяющиеся параметры институциональной среды, что составляет ядро индексов. Ядро индексов представляет собой набор институтов, способствующих повышению эффективности экономической деятельности.

Частичные совпадения используемой для расчета информации могут являться фактором, обуславливающим высокую тесноту связи между различными показателями качества институтов. Но согласованность оценок в не пересекающихся методологически индексах служит доказательством достоверности полученных результатов. Также высокая теснота связи между различными индексами позволяет прийти к выводу, что отдельно взятые индексы качества институтов с наиболее полной информацией могут выступать в качестве количественной оценки качественных характеристик институ- циональной среды в целом и использоваться для межстрановых сопоставлений в экономических исследованиях.

\section{Выводы}

На основании предпринятого исследования можно прийти к следующим выводам:

1. Согласованность оценок в индексах, использующих опросные методы с оценками индексов, применяющих для сбора данных макроэкономическую статистику и прямые измерения, свидетельствует о том, что различные методы дают схожие результаты.

2. Индексы, оценивающие различные параметры качества институциональной среды или построенный на их основе синтетический индекс могут использоваться для получения количественной оценки качества институциональной среды.

\section{Библиографический список}

1. Аджемоглу Дарон Почему одни страны богатые, а другие бедные. Происхождение власти, процветания и нищеты / Дарон Аджемоглу, Джеймс А. Робинсон; [пер. с англ. Д. Литвинова, Павла Миронова, Сергея Сановича].- Москва: Изд-во АСТ, сор. 2015. - 692.

2. Анализ институциональной динамики в странах с переходной экономикой / Л. М. Фрейнкман, В.В.Дашкеев, М.Р. Муфтяхетдинова - М.: ИЭПП, 2009.- 252 с.: ил.- (Научные труды / Институт экономики переход. периода; № 126).

3. Бенсон И.Н. Влияние качества институциональной среды на благосостояние и экономический рост: межстрановые сопоставления // Вестник Санкт-Петербургского государственного университета, серия 5, экономика. 2016. Вып. 3. С. 38-55.

4. Гуриев С., Сонин К. Экономика «ресурсного проклятия». //Вопросы экономики. 2008;(4):61-74. https://doi. org/10.32609/0042-8736-2008-4-61-74

5. Кирдина С. Г. Институциональные матрицы и развитие России: введение в Х-Ү теорию. Издание 3-е переработанное, расширенное и иллюстрированное.- СПб.: Нестор-История, 2014.-468c.

6. Мзоков А.Р. Существующие способы оценки качества государственного управления: WGI и BTI // Наука. Мысль: электронный периодический журнал. 2016. № 12. С. 125-134.

7. Норт Д. Институты, институциональные изменения и функционирование экономики / Пер с англ. А. Н. Нестеренко; предисл. и науч. ред. Б. З. Мильнера. М.: Фонд экономической книги “Начала”, 1997.

8. Норт Д. Понимание процесса экономических изменений. / Дуглас Норт; пер. с англ. Кирилла Мартынова, Николая Эдельмана. - Москва: Изд. дом Гос. ун-та - Высш. шк. экономики, 2010. - 253.

9. Полтерович В.М, Попов В.В., Тонис А.С, Механизмы «ресурсного проклятия» и экономическая политика // Вопросы экономики. 2007. № 6. С. 4-27.

10. Шаститко, А.Е.Новая институциональная экономическая теория / А.Е.Шаститко.- М.: ТЕИС.- 2002.$591 \mathrm{c}$.

11. Lyakin A.N., Benson I.N. Does globalisation lead to the unification of the institutional environment quality? // Proceedings of the 16th International Scientific Conference on Globalization and its Socio-Economic Consequences. Zilina, Slovakia, 2016. pp. 1220-1227

12. Osterfeld D. Prosperity versus Planning: How Government Stifles Economic Growth. New York: Oxford University Press, 1992. 